\title{
1040 Adverse effects of the metabolic deregulation on aortic stiffness and diastolic function in patients with metabolic syndrome assessed with magnetic resonance imaging Stijntje D Roes*, Reza Alizadeh Dehnavi, Jos J Westenberg, Hildo J Lamb, Jouke T Tamsma and Albert de Roos
}

Address: Leiden University Medical Center, Leiden, The Netherlands

* Corresponding author

from I th Annual SCMR Scientific Sessions

Los Angeles, CA, USA. I-3 February 2008

Published: 22 October 2008

Journal of Cardiovascular Magnetic Resonance 2008, I0(Suppl I):AI65 doi:I0.II86/I532-429X-I0-SI-AI65

This abstract is available from: http://jcmr-online.com/content/I0/SI/AI65

(c) 2008 Roes et al; licensee BioMed Central Ltd.

\section{Introduction}

Previous ultrasound studies demonstrated the adverse effect of the metabolic syndrome (MS) on aortic stiffness and left ventricular (LV) diastolic function. However, the exact underlying mechanism responsible for these changes is largely unknown and has not yet been studied with magnetic resonance imaging (MRI).

\section{Purpose}

To evaluate the influence of metabolic deregulation on aortic function and LV diastolic function in subjects with the MS using MRI.

\section{Methods}

MRI was performed in 16 male subjects with the MS and 16 male subjects without the MS who were matched for age, waist circumference and blood pressure. MS was defined using the IDF criteria. Pulse wave velocity (PWV) in the aortic arch and the descending aorta were used as markers for aortic stiffness. Transmitral flow measurements were acquired for evaluation of LV diastolic function. Mean and peak deceleration of the early filling wave (E) were derived. The independent students T-test was used to evaluate differences between the two groups. The association between the separate components of the MS and MRI variables reflecting aortic stiffness and LV diastolic function were calculated using Pearson's correlation coefficient.

\section{Results}

Due to matching, age, waist circumference and blood pressure values were similar between the two groups (age: $60 \pm 5$ and $59 \pm 4$ years, $\mathrm{p}=0.9$, waist circumference: 111 \pm 11 vs. $106 \pm 9 \mathrm{~cm}, \mathrm{p}=0.2$, systolic blood pressure: 145 \pm 17 vs. $142 \pm 17 \mathrm{mmHg}$, $\mathrm{p}=0.6$, diastolic blood pressure: $88 \pm 8$ vs. $89 \pm 9 \mathrm{mmHg}, \mathrm{p}=0.9$ resp. in subjects with and without the MS). PWV in the aortic arch and descending aorta was higher in subjects with the MS (7.6 \pm 2.2 vs. 5.7 $\pm 1.1 \mathrm{~m} / \mathrm{s}, \mathrm{p}<0.01$ and $7.3 \pm 1.9$ vs. $6.1 \pm 1.1 \mathrm{~m} / \mathrm{s}, \mathrm{p}<$ 0.05). LV diastolic function was diminished in subjects with MS compared to subjects without MS (peak E deceleration:-3.7 \pm 1.0 vs. $-4.6 \pm 1.3 \mathrm{ml} / \mathrm{s}^{2}, \mathrm{p}<0.05$ and mean E deceleration:- $2.4 \pm 0.7$ vs. $\left.-3.0 \pm 0.9 \mathrm{ml} / \mathrm{s}^{2}, \mathrm{p}<0.05\right)$. PWV in the aortic arch and total aorta (aortic arch and descending aorta) correlated with HDL-cholesterol (resp. $\mathrm{r}=-0.514, \mathrm{p}=0.003$ and $\mathrm{r}=-0.470, \mathrm{p}=0.007)$. Furthermore, HDL cholesterol correlated with mean deceleration of the $\mathrm{E}$ wave (resp. $\mathrm{r}=-0.421, \mathrm{p}=0.021$ ). No significant correlation was observed between the other components of the MS and aortic or cardiac function.

\section{Conclusion}

Metabolic deregulation in patients with the MS, in particular low HDL-cholesterol, is related with adverse cardiovascular changes, regardless of blood pressure. 